\title{
Febre e adenopatias em mulher jovem de raça negra - caso clínico
}

\section{Fever and lymphadenopathy in a young black female - case report}

\author{
Soraia Oliveira ${ }^{1}$, António Ferreira ${ }^{1}$, Manuel Veiga² ${ }^{2}$ Augusta Silva ${ }^{1}$. \\ ${ }^{1}$ Serviço de Medicina 1, ${ }^{2}$ Serviço de Anatomia Patológica - Hospital de Santa Luzia. Unidade Local de Saúde do Alto Minho (ULSAM). \\ Viana do Castelo. Portugal
}

\begin{abstract}
Resumo
A doença de Kikuchi, também designada linfadenite histiocítica necrotizante, é uma doença rara, autolimitada e de etiologia ainda não esclarecida. A maioria dos casos descritos são em doentes de origem asiática, sendo muito raros os casos em doentes de raça negra. Caracteriza-se frequentemente pela presença de adenomegalias cervicais e febre. Normalmente cursa com evolução favorável, com regressão espontânea da sintomatologia, ocorrendo apenas recidiva em cerca de $4 \%$ dos doentes.

Os autores descrevem um caso clínico raro de recidiva de doença de Kikuchi numa doente jovem, de raça negra que apresentava adenomegalias cervicais e febre. 0 diagnóstico foi estabelecido após realização de biópsia excisional de gânglio e respectivo estudo histológico e imunocitoquímico.
\end{abstract}

Apesar de rara, a doença de Kikuchi deve ser considerada como diagnóstico diferencial no estudo de adenomegalias e febre de causa desconhecida.

Palavras-chave: Doença de Kikuchi; linfadenite histiocítica; adenomegalias cervicais; febre

\section{Introdução}

A doença de Kikuchi-Fujimoto, também denominada linfadenite histiocítica necrotizante, é uma doença rara, de etiologia desconhecida, que afeta sobretudo mulheres com idade inferior a 40 anos. Descrita pela primeira vez no Japão em 19721,2. A sua prevalência é maior em pacientes de origem asiática ${ }^{3,4}$, havendo poucos casos descritos na literatura em doentes de raça negra ${ }^{5}$. Caracteriza-se mais frequentemente por adenomegalias cervicais, associadas a febre em $30-50 \%$ dos casos. Outras manifestações clínicas menos comuns incluem sudorese noturna, náuseas, vómitos, perda ponderal, diarreia, mialgias, artralgias, hepatoesplenomegalia e exantema. 0 diagnóstico definitivo baseia-se em achados histopatológicos: foco único ou múltiplos paracorticais usualmente com necrose e infiltrado celular histiocítico. A histologia varia com a evolução da doença. Estão descritas 3 fases histológicas de acordo com a evolução da doença: fase proliferativa; fase necrotizante e fase xantomatosa ${ }^{4,6} .0$ estudo imunocitoquímico evidencia predomínio de linfócitos T CD8 e CD4 positivos e histiócitos CD68 positivos. Nos diagnósticos diferenciais incluem-se as doenças linfoproliferativas, as doenças infecciosas associadas a necrose ganglionar e o lupus eritematoso sistémico (LES) 3,4. A evolução da doença é normalmente benigna, com regressão espontânea da sintomatologia e a maioria dos doentes não necessitam de tratamento ou este é apenas sintomático $0^{3,4,7}$. A corticoterapia está indicada apenas em casos graves ${ }^{6}$. As recidivas são raras (até $4 \%$ dos doentes) $)^{3,4}$.

\begin{abstract}
Kikuchi's disease, also called histiocytic necrotizing lymphadenitis, is a rare, self-limited disease, whose etiology remains unclear. Most cases are reported in patients of Asian origin, being very rare in black patients. Often characterized by the presence of cervical lymphadenopathy and fever. Usually presents with favorable outcome with spontaneous regression of symptoms, relapse occurring only in about $4 \%$ of patients.

The authors describe a rare clinical case of recurrent Kikuchi's disease in young black female patient who had cervical lymphadenopathy and fever. The diagnosis was established after undergoing excisional biopsy ganglion and the histological and immunohistochemical study.

Although rare, Kikuchi's disease should be considered as a differential diagnosis in the study of lymphadenopathy and fever of unknown cause. Keywords: Kikuchi's disease; histiocytic lymphadenitis; cervical lymphadenopathy; fever
\end{abstract}

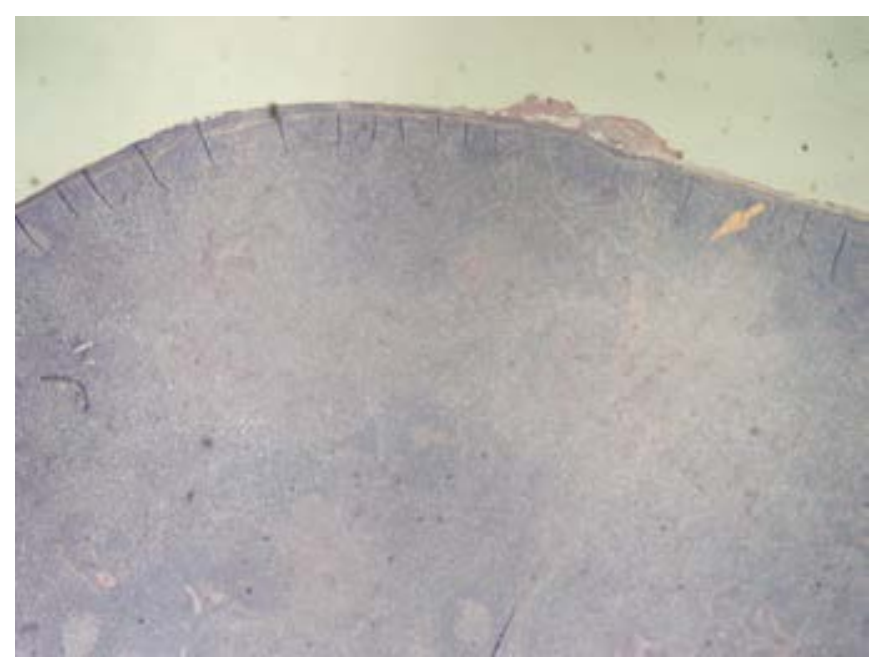

\section{Caso clínico}

Doente, sexo feminino, 22 anos, raça negra, natural e residente em Portugal, previamente saudável, observada no serviço de urgência por febre com evolução de 1 mês associada a adenomegalias cervicais bilaterais, odinofagia, hipersudorese noturna e astenia. Estava medicada com paracetamol e ibuprofeno desde o início dos sintomas sem melhoria clínica. Ao exame físico estava febril (Ta: $39^{\circ} \mathrm{C}$ ) e apresentava volumosas adenopatias cervicais posteriores e submandibulares bilateralmente, móveis, duras e dolorosas à palpação, a maior com $2 \mathrm{~cm}$. Analiticamente com velocidade de se- 
dimentação elevada (VS > 140mm), anticorpos VIH 1-2 não reactivo e imune para Toxoplasmose, Citomegalovírus (CMV) e Epstein-Barr (EBV). A ecografia cervical revelou várias adenomegalias. Realizou radiografia do tórax - sem alterações, e a prova de Mantoux que foi negativa. 0 quadro clínico foi inicialmente interpretado como síndrome mononucleósica e foi reavaliada 3 semanas depois. Nessa altura estava assintomática, sem febre e não se palpavam adenomegalias. Repetiu controlo analítico com normalização do valor da VS (8mm). A reação de Paul-Bunnel e as serologias para Herpes I e II foram negativas. Repetiram-se também as serologias para Toxoplasmose, CMV, EBV e VIH com resultados sobreponíveis às análises prévias. Os anticorpos antinucleares (ANA) foram negativos. Um mês depois, apresentou recidiva do quadro clínico, tendo-se realizado biópsia excisional de adenopatia cervical, cujo estudo histólógico evidenciou gânglio linfático com hiperplasia folicular reativa e vários focos de necrose (Figura 1) com proliferação de histiócitos e macrófagos com restos celulares, associados a linfócitos reativos, sem evidência de neutrófilos nem células atípicas. 0 estudo imunocitoquímico mostrou positividade nas áreas necróticas para CD68 (Figura 2) e CD3 e negatividade para CD20 e Bcl-2. Portanto os achados morfológicos foram compatíveis com Linfadenite Necrotizante Não-Granulocítica (Doença da Kikuchi). A doente apresentou melhoria clínica espontânea, sem nova recidiva até ao momento.

\section{Discussão}

A Doença de Kikuchi é uma doença rara que afeta predominantemente mulheres jovens, havendo poucos casos descritos na literatura em pessoas de raça negra. A sua etiologia é desconhecida, tendo sido descritas associações a algumas infeções víricas, mas também sugerida a etiologia auto-imune ${ }^{6}$. 0 diagnóstico diferencial inclui várias patologias, nomeadamente, as doenças linfoproliferativas, a tuberculose ganglionar, a toxoplasmose, entre outras. Como o tratamento para cada um dos diagnósticos diferenciais é bastante distinto, é de extrema importância o correcto diagnóstico da doença de Kikuchỉ, ${ }^{3,7} 0$ qual é feito com base em achados histopatológicos.

A doença é auto-limitada, com resolução clínica que varia entre algumas semanas e até 6 meses. Normalmente com evolução benigna, no entanto, há casos descritos com envolvimento multissistémico e desfecho fatal. A terapêutica é sintomática, podendo-se recorrer a corticoterapia em casos clínicos graves ${ }^{6}$. A possível associação com o LES implica necessariamente o seguimento e vigilância destes doentes a longo prazo 5,7 .

Este caso clínico é único pois, sendo a doença de Kikuchi rara é ainda menos frequente em doentes de raça negra. Além disso descreve-se também outro aspecto raro nesta doença que é a sua recidiva e não resposta inicial aos analgésicos e anti-inflamatórios. Salienta-se a importância da biópsia que neste caso foi fundamental para o diagnóstico.

\section{Bibliografia}

1. Kikuchi M. Lymphadenitis showing focal reticulum cell hyperplasia with nuclear debris and phagocytosis. Acta Haematol Jpn 1972; 35: 379-80

2. Fujimoto $Y$, Kojima $Y$, Yamaguchi K. Cervical subacute necrotizing lymphadenitis. A new clinicopathological entity. Naika 1972; 20: 920-7

3. Tariq H, Gaduputi V, Rafiq A, Shenoy R. The Enigmatic Kikuchi-Fujimoto Disease: A Case Report and Review. Case Reports in Hematology. 2014; 2014: Article ID 648136.

4. Vicente A, Araújo J, Oliveira H, Matos M. Doença de Kikuchi-Fujimoto num doente de raça negra. Medicina Interna, SPMI. 2012; 19 (2): 74-8.

5. Luis C et al. Doença de Kikuchi. Acta Pediatr Port 2008; 39(6): 240-2

6. Reichert A, Correia T, Freitas O, Almeida T, Rosado L. Doença de Kikuchi e Fujimoto. Acta Méd Port 2005; 18: 231-4

7. Rezayat T, Carroll M, Ramsey B, Smith A. A Case of Relapsing Kikuchi-Fujimoto Disease. Case Reports in Otolaryngology. 2013; 2013: Article ID 364795.

Figura 2. Imunocitoquímica com CD68. Observam-se macrófagos espumosos (seta).

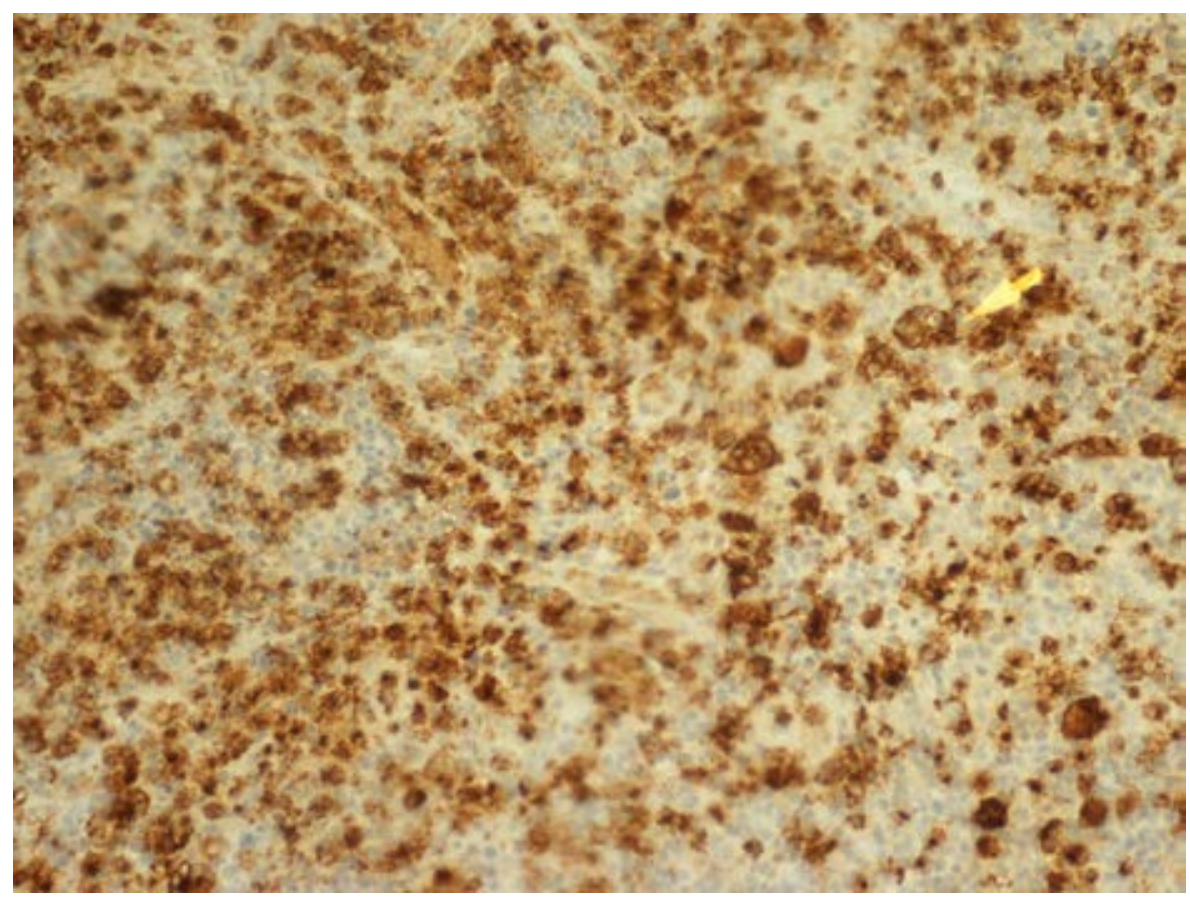

